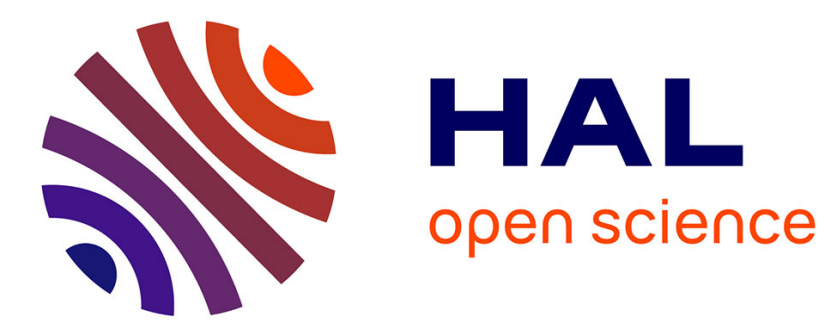

\title{
Use of Heuristics to Facilitate Scientific Discovery Learning in a Simulation Learning Environment in a Physics Domain
}

\author{
Koen Veermans, Wouter van Joolingen, Ton de Jong
}

\section{To cite this version:}

Koen Veermans, Wouter van Joolingen, Ton de Jong. Use of Heuristics to Facilitate Scientific Discovery Learning in a Simulation Learning Environment in a Physics Domain. International Journal of Science Education, 2006, 28 (4), pp.341 - 361. 10.1080/09500690500277615 . hal-00197360

\section{HAL Id: hal-00197360 https://telearn.archives-ouvertes.fr/hal-00197360}

Submitted on 14 Dec 2007

HAL is a multi-disciplinary open access archive for the deposit and dissemination of scientific research documents, whether they are published or not. The documents may come from teaching and research institutions in France or abroad, or from public or private research centers.
L'archive ouverte pluridisciplinaire HAL, est destinée au dépôt et à la diffusion de documents scientifiques de niveau recherche, publiés ou non, émanant des établissements d'enseignement et de recherche français ou étrangers, des laboratoires publics ou privés. 
This is an electronic version of the article published in: Veermans, K.H., Van Joolingen, W.R., \& Jong, T. de (2006).

Use of Heuristics to Facilitate Scientific Discovery Learning in a Simulation Learning Environment in a Physics Domain. International Journal of Science Education, 28, 341-361 @ 2000 Taylor \& Francis, available online at: http://www.informaworld.com/openurl?genre $=$ article\&issn $=0950-0693 \&$ volume $=28 \&$ issue $=4 \&$ spage $=341$

RUNNING HEAD: HEURISTICS TO FACILITATE DISCOVERY LEARNING

Use of Heuristics to Facilitate Scientific Discovery Learning in a

\title{
Simulation Learning Environment in a Physics Domain
}

\author{
Koen Veermans ${ }^{1}$ [e-mail: koevee@utu.fi], Wouter van Joolingen ${ }^{2}$, \& Ton de \\ Jong $^{2}$ \\ ${ }^{1}$ Educational Technology Unit, University of Turku, FI-20014 Turku, Finland. \\ ${ }^{2}$ Faculty of Behavioral Sciences, University of Twente, PO Box 217, 7500 AE
}

Enschede, The Netherlands

This article describes a study into the role of heuristic support in facilitating discovery learning through simulation-based learning. The study compares the use of two such learning environments in the physics domain of collisions. In one learning environment (implicit heuristics) heuristics are only used to provide the learner with guidance derived from heuristics, without presenting the heuristics themselves, in the other (explicit heuristics) the heuristics themselves are also made explicit to the learner. The two learning environments are tested with 46 students from two schools. The results show that learners in both conditions gain domain knowledge from pre-test to post test. Regression analyses show that pre-test results can predict post-test results in the implicit heuristics condition but not in the explicit heuristic condition. Process analyses suggest that presenting the heuristics explicitly facilitate more self-regulation in students.

\section{Introduction}

Discovery learning has seen a resurgence in popularity over the last decade for at least two reasons. One reason is a tendency towards more learner-centered instead of teacher-centered education. The discovery learning of science, with its emphasis on developing a self-attained grasp of a phenomenon through active inquiry of that phenomenon (Zachos et al., 2000) fits rather well within a learner-centered approach. The other reason lies in the wide availability of computers that inspired people to develop powerful simulation-based learning environments for scientific discovery learning. 
In the discovery learning of science with computer simulations, learners address given problems in a scientific way (de Jong \& van Joolingen, 1998). A main advantage of simulations is that they provide a constrained environment (de Jong, 1991). They are constrained because they are based on the experimental frame (van Joolingen \& de Jong, 1991) that defines the simulation, that is, the set of variables that the user can manipulate and observe as determined by the designer of the simulation. Hence the simulation reflects the designer's theoretical views on the domain. This characteristic distinguishes simulation-based scientific discovery learning from other forms of discovery learning, that often provide a less structured environment, as has often been criticized (Hodson, 1996, 1998; Mayer, 2004).

These methods used by students include, for instance, choosing values for variables in experiments, plotting values of variables to interpret results, answering questions, formulating hypotheses, and many more (Friedler et al., 1990; Krajcik et al., 2000; Kuhn et al., 2000; Lewis, 1993; Njoo \& de Jong, 1993; White, 1993). When learners possess the skills that are needed to carry out these methods, scientific discovery learning will be motivating (Minstrell, 2000), and lead to integrated knowledge about the domain (Schauble et al., 1991). However, when learners experience problems with these methods, which is often the case (de Jong \& van Joolingen, 1998; Klahr \& Dunbar, 1988; Kuhn et al., 1992; Quinn \& Alessi, 1994; Reimann, 1991; Shute \& Glaser, 1990), support should be provided.

There are three main approaches to providing such support: one can try to teach scientific discovery skills, try to offer support during that process from within the learning environment, or try to offer support within the learning environment that allows learners to become competent at discovery learning. 
Teaching general discovery learning skills before actually engaging in the activity has severe drawbacks. First of all, it has been claimed that there is not a single scientific method, but that there are methods dependent of the actual science domain in which discovery takes place (Hodson, 1998). Although it can be argued that scientific methods have common elements, there are reasons to assume that transfer from a general teaching scenario to a specific learning context may not take place. Built-in support tries to shield learners from potential problems that they might encounter during discovery learning, and has been tried out in many studies by offering cognitive tools to learners. Cognitive tools that scaffold learning processes take over part of the process, for instance, by externalizing learning processes, or structuring the task (Lajoie \& Derry, 1993; van Joolingen, 1999). For example, a learning environment may contain dedicated notebooks that allow learners to take structured notes, tools to manipulate data, and/or forms with explicit steps to be taken by the learner (Shute \& Glaser, 1990; van Joolingen \& de Jong, 1997). If applied and implemented carefully, the learner will be guided through the environment, and will be able to acquire knowledge about the domain along the way. The third approach is a combination of the first two, where the function of guidance is to support the learner in the current situation, and to teach underlying discovery learning principles that transfer to new situations.

A potentially fruitful way for implementing this approach is to use heuristics; rules of thumb that can help to reach a certain goal in a complex problem-solving situation (Polya, 1945, 1971; Schoenfeld, 1979, 1985). Heuristics have characteristics that make them suitable for both guidance, and transfer purposes. The latter requires the learner to acquire explicit knowledge of the heuristics, acquired through own 
abstraction, or from a learning environment that presents the heuristics in an explicit way.

Heuristics can provide a powerful means for making decisions in a discovery learning process. A typical discovery process does not allow a complete and exhaustive analysis of the problem and the context, and decisions need to be made based on incomplete information. Therefore, heuristics can play an important role in shaping a discovery process. Table 1 presents an overview of heuristics used in this study. The heuristics stem from an inventory by (Sanders et al., 2000).

Insert Table 1 about here

Most heuristics in Table 1 apply to the kind of inquiry that is typically found in simulation-based inquiry environments. They are specific enough to elicit concrete behavior and general enough to be of use in multiple simulations. A characteristic of heuristics is that they can be fallible, i.e., they might lead to wrong decisions. This can be illustrated with VOTAT (vary one thing at a time) a heuristic related to experimental design (Tsirgi, 1980). This heuristic (sometimes also referred as controlling variables) is generally considered to be important and has been the focus of studies (Chen \& Klahr, 1999; Schauble et al., 1995) or given as hint to students before (Rivers \& Vockell, 1987) or during experimentation (Lavoie \& Good, 1988). The idea behind it is that by changing only one thing (in the case of simulations: a variable value) at a time, differences between the outcomes of the experiments can be attributed to the one thing that was changed. However, as Zohar (1995) argues, this principle does not work in situations with interacting variables where it is necessary 
to look at situations in which more than one variable is changed. Therefore, apart from the utility of heuristics, their limitations must also be taught.

Heuristics can vary in the range of situations in which they can be applied, they can depend more or less on the domain and also be more or less general. Varying the use of heuristics in a learning environment along these dimensions can make learners aware of the heuristics’ potential use. This can increase the probability of transfer to occur, as both the heuristic itself as its domain of application can be observed by the learner. In instruction, heuristics can be made explicit to the learner or kept implicit. Embedding a heuristic implicitly in a learning environment by providing the learner with hints and guidance derived from a heuristic can be augmented by presenting the heuristic itself. Implicit heuristics in a learning environment may result in successful behavior within the learning environment, but it is unrealistic to expect transfer to other domains or situations.

\footnotetext{
Aims

The aim of the current study was to examine whether offering heuristics for discovery learning can engage learners in discovery learning processes in which they learn about the domain of head-on collisions and, through the heuristics, about the processes of discovery learning. The goal of the learning environment therefore was to learn science and to learn about science (Hodson, 1996). The domain of collisions was chosen because it can be described with a limited number of variables, which can be combined in formulas based on mass and velocity, but also in terms of general laws of energy and momentum that are not so easily discovered. The study also explores differential effects of implicit and explicit presentation of heuristics on knowledge and discovery behavior.
} 


\section{Design of the study}

Two learning environments were designed for the present study, one that incorporates heuristics only implicitly, and a second that incorporates heuristics both implicitly and explicitly. The two learning environments are built around the same simulations and contain the same set of cognitive tools to support the learners. The heuristics in Table 1 are used in the design of these cognitive tools. In addition, the explicit version of the learning environment presents information about the heuristics to the learner. Both learning environments employ a fading approach in which the support from the heuristics is gradually decreased.

Students are supported by cognitive tools in both conditions, therefore it is expected that students acquire knowledge about the domain in both conditions. Because students in the explicit condition need to process additional information about the heuristics, they are expected to need more time for the learning process at the start than students in the implicit condition. In line with Schoenfeld, 1985, who found that only explicit teaching of heuristics to students resulted in use of the heuristics later on, the difference between explicit and implicit is expected to result in differences in knowledge about and use of the heuristics. When the support is fading these differences are expected to show in the interaction with the environment. Students in the explicit condition are expected to be able to transfer heuristics, and keep on using them, whereas only part of the students in the implicit condition is expected to be able to do so.

\section{Method}

\section{Participants}

Participants were 30 Dutch students from two schools: 17 students from one school, 13 students from the other. The students took part in the study on a voluntary basis. 
The students were in their fifth year of pre-scientific education (16-17 year-olds). All students attended physics classes and had sufficient computer experience. The students within a school class were distributed randomly over the two conditions. In the implicit condition one participant did not complete the knowledge pre-test. This participant is excluded from analyses where these test scores are needed. In the explicit condition one participant answered the post-test so quickly that it is most likely that the answers were randomly given. This participant is excluded from all analyses.

\section{The learning environment}

The learning environments in this study are adapted versions of the Collision environment (Swaak et al., 2004). The learning environment uses model progression, assignments, an experiment storage tool, background information, and feedback explanations to support learners.

There are four model progression levels in the learning environment (White \& Frederiksen, 1990). On the first level students can change the force exerted on a ball or the mass of the ball and investigate the relation between the force and the resulting velocity, and between the force and the resulting momentum (dt and applied force during dt were constant in this simulation). Students had prior knowledge about force, and this knowledge is used to introduce momentum, a key concept in collisions. The second level is about elastic collision of a ball against a fixed wall. The third level also deals with elastic collisions, but now 1-dimensional collisions between two balls. The final level is about 1-dimensional inelastic collisions.

Each level includes a simulation. Figure 1 shows the simulation interface of the third level (elastic collisions). The simulation interface contains an animation of the movement of the ball(s). Diagrams plotting position and velocity of the ball(s) against 
time are shown. The last three levels also show kinetic energy of the two colliding particles in a third graph. Under the animation and graphs, numerical values of variables are shown. Input variables are located towards the left side of the simulation window, output variables towards the right side. Students can increase or decrease the values of the input variables by clicking on the arrows next to the value, or by typing in a new value. The students can control the simulation with buttons on the bottom of the simulation window.

Insert Figure 1 about here

Each level contains assignments to support the students. The first level contains seven assignments, the second level five, the third level fourteen, and the fourth level thirteen. The first one or two assignments are an introduction to the level (e.g., introducing the relation between animation and the graphs). The introductory assignments are followed by assignments that ask learners to investigate relationships between input and output variables (e.g., relation between force and velocity for movement of a ball in Figure 2). The final assignment on a level concludes work at that level, or draws the attention to important issues related to that level (e.g., conservation of energy in the case of elastic collisions). Students are not forced to do assignments in the given order; they are free to choose any assignment at any moment in time. However, the names of the assignments, starting with a number, suggest a preferred order.

Insert Figure 2 about here 
A tool that allows learners to store the results of experiments accompanies all assignments that investigate relationships between input variables and output variables. This tool shows the input variables as well as the output variable(s) of interest for the current assignment. Apart from keeping track of experiments, the tool also allows students to draw graphs based on the experiments, fit functions through the experiments, and construct new variables.

Insert Figure 3 about here

\section{Implementation}

The heuristics from Table 1 are included in the design and content of the learning environment. Figure 2 and Figure 3 show the differences between the instructional support measures included in both versions of the learning environment. The model progression levels for instance implement the 'simplify the problem' heuristic by dividing the domain into parts that can than be investigated by the learners. Assignments are offered to the learners on each model progression level, and within these assignments a number of heuristics are included. If possible the 'simplify the problem' heuristic is used at the start of a model progression level to create an assignment that is relatively easy to investigate. Later assignments use the 'slightly modify hypothesis' and 'set expectations' heuristic to address a broader range of situations and to see whether the findings from the simpler problem are valid in this broader range of situations. The 'vary one thing at a time' heuristic is included in the assignments by focusing on a relationship between one input and one output variable within an assignment, and by stressing that other variables should be kept the same over a series of experiments within such an assignment. A series of experiments is set 
up in a way that it complies with the 'simple values', 'equal increments', and occasionally 'extreme values' heuristics. At the same time the 'keep track' heuristic is included by stressing the necessity to keep records of their experiments. The 'draw graph' and 'confirm hypothesis' heuristics are included in assignments, the experiment storage tool and their respective feedback. The 'present evidence' is included in feedback on incorrect answers. The feedback in the assignments also contains references to other heuristics if these can be related to the answer.

The difference between the implicit and explicit heuristics condition is that in the implicit condition the student only receives guidelines derived from the heuristic. The students are told the steps that have to be taken in order to obtain enough information to reach a conclusion on the assignment goal. In the explicit condition these steps/guidelines are accompanied by the heuristic that they were derived from. For instance, use of the 'simplify the problem' heuristic may suggest setting the velocity of the second ball $\left(v_{2}\right)$ to zero. In the implicit condition the assignment just sets $v_{2}$ to zero. This also happens in the explicit condition, but the student will also see the name of the heuristic and why the heuristic relates to setting $v_{2}$ to zero in this case. Feedback on a learner's behavior in an assignment is treated in a similar way: the implicit condition presents only feedback that could be derived from a heuristic, the explicit condition presents information about the heuristic itself as well. In both learning environments heuristics are faded gradually, which means that in the beginning heuristics and concrete guidelines derived from the heuristics (explicit version) or concrete guidelines only (implicit condition) are presented to the learner and that these are replaced gradually by abstract guidelines (if possible) and until some eventually disappear. Guidelines for a heuristics like ‘equal increments’ start with explicit numbers (e.g. 10, 20, 30) on the first two levels, proceed with stepwise (e.g. 
steps of 10) on level three, and are absent on level four. The heuristics ('simple values', 'extreme values’, ‘make a graph', and 'keep track' follow similar trajectories, others are faded more slowly.

The experiment storage/graphing tool also has two versions. In the both conditions the tool can draw a graph and estimate a fit for functions. In the implicit condition the graph is accompanied by a short text that suggests that learner looks at both fit estimation and graph to see if the function fits through the experiments. In the explicit condition the graph also includes feedback on the heuristics, in Figure 3 it reminds the students, for instance, of the 'change one variable at a time' heuristic.

\section{Knowledge measures}

Three tests were administered to assess the students' knowledge; a definitional domain knowledge test and an intuitive domain knowledge test to measure domain knowledge, and a scientific reasoning test to see whether heuristics transfer to general scientific reasoning and experiment design. The two domain knowledge tests were used because of previous experiences with differences in knowledge development between definitional and intuitive knowledge (Swaak \& de Jong, 2001; Veermans et al., 2000). The tests for measuring definitional and intuitive knowledge are identical to the ones used in Swaak et al., 2004. The scientific reasoning test consists of a multiple choice part that will be referred to as the scientific reasoning test, and an experiment design question that will be referred to as the experiment design test.

In the definitional knowledge test the students have to answer questions about the formal/static properties of the domain. The test consists of three-answer items in which students have to choose a correct formula, a general law, or the unit for a 
certain quantity. The definitional knowledge test consists of 20 items, and students are allowed to return to previously answered items.

The intuitive knowledge test intends to measure knowledge about the informal/dynamic properties of the domain (Swaak \& de Jong, 2001). Each item contains three parts: start situation, event, and end situation. The start- and three possible end-situations are shown in graphs, and the event is described in text. Students have to decide which end situation is the result of the event. The intuitive knowledge test consists of 24 three-answer items, and students can not return to previously answered items.

The scientific reasoning test contains translated questions from the ACT science tests (ACT, 2001). These questions focus on the design of experiments and the interpretation of experimental results. In addition, some questions regarding interpretation of information presented in tables, diagrams, and figures were included. Students receive fragments describing research and data carried out by others, and have to answer one or more multiple-choice questions about each fragment. Each of the fifteen questions has four answer alternatives. Figure 4 shows one of the data interpretation questions from this test.

Insert Figure 4 about here

Finally, students had to design an experimental research set-up. The topic is plant growth in a greenhouse, and the students are supposed to set up a research design to find out how amount of water, temperature and light influence plant growth in a 
greenhouse. The number of variables is restricted to three to make it a non-trivial task that is at the same time not too time consuming.

Students' interactions with the learning environment were gathered in log files and used to extract information about the students' interaction with the learning environment. The amount of time that students worked on each assignment, within each model progression level as well as the total time on task, were recorded. For each model progression level, the number of experiments, the number of unique experiments, and the number of graphs drawn, was extracted from the log files. For assignments it was checked whether students followed the experimentation guidelines and/or drew a graph and time spent and the number of experiments were also counted. These figures were aggregated for each model progression level to provide a global picture of the students' interaction with the learning environment.

\section{Procedure}

The session lasted approximately three hours, and included the following sequence of events:

- $\quad$ Introduction and pre-tests (40 minutes).

Participants are welcomed and given an overview of the activities in the session. After this short introduction, the definitional knowledge and intuitive pre-test are administered electronically.

- Interaction with Collision (set at 1 hour and 40 minutes).

After the introduction, participants work with the Collision environment individually. Two experiment leaders are present and available for questions related to operating the environment, but not for questions concerning subject 
matter. Participants are encouraged to use the full time available for the interaction. If they want to finish earlier they are asked to explore the environment more, but not forced to do so.

- $\quad$ Post-tests (40 minutes).

After the interaction with the learning environment the post-tests are administered. The definitional knowledge test is administered first, followed by the intuitive test, and the scientific reasoning test. The scientific reasoning test is a paper and pencil test.

\section{Results}

\section{The Knowledge Measures}

The reliability of the definitional knowledge test was 0.39 on the pre-test and 0.63 on the post test. For the intuitive knowledge test, the reliability was 0.71 on the pre-test and 0.64 on the post test. The reliability of the scientific reasoning test was -0.64 as a result of a ceiling effect, small variance, and no systematic relation between score and incorrect answers. The experiment design question was rated on a five-point scale by two independent raters. They reached agreement on their ratings afterwards. Interrater reliability between the raters was $(\mathrm{k}=0.81)$ and between each rater and the final score (rater 1-final, $\mathrm{k}=0.84$, rater 2-final, $\mathrm{k}=0.90$ ).

Table 2 presents an overview of the mean scores and standard deviations for the different knowledge tests. The definitional knowledge test and the intuitive knowledge test are assumed to measure different types of knowledge in students (Swaak \& de Jong, 2001), with definitional knowledge being more static (knowing the underlying definitions and formula's in a domain) and intuitive knowledge more 
dynamic (knowing what will happen in a certain situation). The low correlation between the two pre-tests (implicit condition 0.11, explicit condition -0.03 , both conditions 0.08), supports this assumption.

Insert Table 2 about here

It was expected that students in both conditions would gain on both types of knowledge, while working with the learning environment. Paired samples t-test comparison of the pre- and post-test results on the definitional knowledge test (overall: $\mathrm{t}(27)=8.55, \mathrm{p}<0.001$, implicit: $\mathrm{t}(13)=6.12, \mathrm{p}<0.001$, and explicit: $\mathrm{t}(13)=$ 5.87, $\mathrm{p}<0.001$ ), and the intuitive knowledge test (overall: $\mathrm{t}(28)=7.50, \mathrm{p}<0.001$, implicit: $\mathrm{t}(14)=6.04, \mathrm{p}<0.001$, and explicit: $\mathrm{t}(13)=4.63, \mathrm{p}<0.001)$, confirm this prediction. Effect sizes (d) for definitional and intuitive knowledge gain are large in both conditions with 1.46 (implicit) and 2.18 (explicit) for definitional knowledge, and 1.15 (implicit) to 1.40 (explicit) for intuitive knowledge. No differences are found between the two conditions on the definitional post-test $(\mathrm{t}(27)=-0.60, \mathrm{p}=0.56)$, or between the two conditions on the intuitive post-test $(t(27)=-0.37, p=0.71)$. Students in both conditions scored high on the scientific reasoning test with no difference between the two conditions $(\mathrm{t}(27)=-0.43, \mathrm{p}=0.67)$. The high scores, small variance, and reliability suggest a ceiling effect on this measurement. The experiment design question also did not show any differences $(\mathrm{t}(21.7)=-0.44, \mathrm{p}=0.66)$. Overall, the results suggest that the effect of the learning environment on knowledge is the same in the both conditions, however, based on experience from a previous study in which a more complicated picture arose from relations between the different test scores (Veermans et al., 2000), these relations are also examined. 
Relations between pre- and post-test knowledge measures

The relations between the pre-test and post-test scores provide information on the way the students respond to the learning environment. When all students respond to the learning environment in a similar way, the ranking of the students will remain more or less the same between pre- and posttest. In this situation a high rank correlation between (similar) pre- and post-tests would be expected.

As can be seen in Table 3, in the implicit heuristics condition the rank-correlation between the definitional pre- and post-test (0.59), and between the intuitive pre- and post-test (0.57) suggest that the students respond to the treatment in more or less the way that might be expected. In the explicit condition this is not the case. In this condition the pre-test score is not related with its post-test counterpart on the definitional knowledge test, and only moderately with the intuitive knowledge test

Insert Table 3 about here

These results are examined in more detail with a regression analysis that uses the pretest scores to predict the post-test scores. This shows how well post-test scores can be predicted from pre-test scores and to what extent the different pre-tests contribute to the prediction.

Table 4 shows the results of the regression analysis for the definitional knowledge test. It shows that, for the implicit condition, the definitional post-test result can be predicted based on the pre-test results. The regression function also shows that this prediction is mainly derived from the definitional knowledge, although the intuitive knowledge contributes to the prediction as well. In the explicit condition the 
regression analysis is not significant, and what is also striking is that the definitional pre-test knowledge does not contribute to the prediction of the definitional post-test.

Insert Table 4 about here

Table 5 presents the results of the regression analysis for the intuitive knowledge test. Again, in the implicit condition the scores post-test can be predicted based on the pretest results. This time the prediction is almost solely derived from the intuitive pretest. Again, in the explicit condition the regression analysis is not significant. This means that, for both definitional and intuitive knowledge, students from the lower ranges on the pre-test are gaining more knowledge than students from the higher ranges. Of course they have more knowledge to gain (a student with 8 out of 20 has more to gain than a student with 12 out of 20), but lower scoring students are even passing higher scoring students in the explicit condition (e.g., the first student improving to 16 and the second to 15$)$.

Insert Table 5 about here

\section{Process measures}

It was expected that students in the two conditions would differ in their interaction with the learning environments on the first level, when the students are confronted with the implicit and/or explicit heuristics for the first time. Table 6 shows indicators of student interaction with the learning environment on the first level. Contrary to the expectations, there is neither difference in time that students spent on the first level, nor in time spent working on assignments on this level. The difference in the number 
of unique experiments with the simulation is not significant, and the total number of experiments is quite similar. Differences were found only in relation to following the guidelines in the assignments. Students in the implicit heuristics condition followed the experimentation heuristics in assignments 3 to 6 more often literally than students in the explicit heuristics condition did. They also drew graphs in more assignments than the students in the explicit heuristics condition.

Insert Table 6 about here

After the first two introductory assignments, the students were confronted with the heuristics for the first time in assignments 3 to 6 . Each of these assignments asks the students to investigate a certain relation between two variables with a series of experiments and by drawing a graph. Table 7 shows the behavior of students on these assignments. Students were counted only if they conducted the exact same experiments in the same order as given in the assignment.

Insert Table 7 about here

What can be seen from these results is that almost all students in the implicit condition literally followed the experimentation guidelines in assignment 3 and 5. Only in assignment 4 about half of the students deviated from the heuristics in the assignment. The students in the explicit condition showed quite different behavior, with about half of the students following the heuristics literally in assignment 3 and 5, and almost no one in assignment 4 . In assignments 3 to 5 students are also requested to draw a graph of the results of their experiments based on the "draw a graph" heuristic with the idea 
that it makes the interpretation of the results easier. Although the pattern is not as strong, a similar pattern as for standard experimentation can be seen. Students in the implicit heuristics condition are drawing graphs more often than students in the explicit heuristics condition. These results suggest an effect on the way that students work depended on the learning environment condition (explicit or implicit), and that surprisingly enough this effect does not affect the time spent on the first level. The students in the explicit condition seem to more self-regulating, whereas the students in the implicit condition seem more regulated by the environment. The difference in behavior does however not propagate clearly to levels three (elastic collisions) and four (inelastic collisions) ${ }^{1}$. On these levels students can not be differentiated based on similar process measures.

\section{Relations between process and knowledge measures}

The previous section compared behavior of the students in the two conditions while working with the learning environment. The results show differences at the first level, which were not sustained at the next level. Does this mean that the differences only exist at the beginning and that students in both conditions work and learn in the same way on the other levels? In an attempt to answer this question, this section explores some of the relations between the process measures and the knowledge measures. The general idea is that, if students work and learn in similar fashion on these levels, correlations between process measures and the test results should also be comparable. Table 8 shows the correlations between definitional post-test score and process measures on levels three (elastic collisions) and four (inelastic collisions).

\footnotetext{
${ }^{1}$ In the explicit condition of the first session students could not change the value of one of the variables on the second level as a result of a technical problem. As a result the second level was not fully comparable in both sessions. The results will therefore only be shown for levels three and four.
} 
The results in Table 8 show a number of differences between the two conditions. Most striking are the differences with respect to experimenting within assignments. In the implicit condition the correlation between both total number and unique number of experiments within assignments and definitional post-test score is negative. In the explicit condition it is positive. The correlation between the number of assignments in which students draw a graph and the definitional post-test score is also positive in the explicit condition. Total experiments and total unique experiments have less strongly correlated with definitional post-test score. In general, correlations between process measures and definitional post-test score tend to be negative in the implicit condition, and positive in the explicit condition. For the intuitive knowledge post-test scores, this relation is not found.

\section{Conclusion}

The aim of this study was to examine whether heuristics for scientific discovery learning can engage learners in a learning process in which they learn domain knowledge as well as knowledge about the process of scientific discovery. Offering heuristics explicitly was investigated as a means for the acquisition of knowledge about scientific discovery. It is important that learners acquire domain knowledge in the same context as acquiring knowledge about scientific discovery, because learning about a domain provides the meaningful context in which application of the heuristics can prove to be valuable. Our results show a considerable gain, with large effect sizes, on both definitional and intuitive knowledge from pre- to post-test for the students in 
both conditions. However, it is less easy to establish the relation between these gains and the learners' actual behavior in the learning environment.

We expected that learners receiving explicit heuristics would need more time to process the information offered, especially at the start of the learning experience. The analysis of the behavior of the students shows that there are some differences in behavior at the start, but not the expected difference in time. Students in the implicit condition carefully follow the implicit heuristics at the start. Students in the explicit condition more often deviate from the implicit heuristics and follow their own plans. They make own decisions about experimenting (more, less, different), and the need to draw a graph. Later on, these differences seem to disappear, meaning that the students in the implicit condition start working according to their own plans as well. Fading the support more or less forces them into a way of working comparable to the students in the explicit condition. However, this is not supported by relations between process measures and the post-test scores. The general tendency seems to be that in the explicit condition students who still show orderly discovery behavior on the third and fourth level, by experimenting, and drawing graphs of their experiments, score high on the definitional knowledge post-test. The implicit condition shows a relation in the other direction; here the more active students score low on the definitional knowledge post-test. This could indicate that at least some students in the implicit condition do not really know how to deal with the implicit heuristics. They learn to apply them, without really grasping the ideas behind them. It seems that only part of the students can cope with the fading support in the implicit condition, and that those who can are not the ones trying to use heuristics.

Analyses of the relation between pre-test and post-test scores also show differences between the two conditions with respect to how students respond to the learning 
environments. The most striking difference is the strong relation between the definitional pre-test score and the definitional post-test score in the implicit condition and the absence of such a relation in the explicit condition. The regression analysis that predicts the post-test score based on the pre-test score shows that the prediction is much better for both types of knowledge in the implicit condition. It shows that in the explicit condition, students who score lowest on the pre-test are not necessarily scoring lowest on the post-test, and students who score highest on the pre-test are not necessarily scoring highest on the post-test. This means that if the definitional knowledge is taken as the discriminator between strong and weak students, the explicit condition changes this ranking from pre- to post-test more than the implicit condition thus favoring at least part of the weaker students. This could suggest that offering explicit heuristics may be especially beneficial for the weaker students. For science education this provides a case for explicit teaching of the way scientists work, not only at the abstract method level, involving hypothesis generation and testing, but at more practical level, involving the actual domain specific and general heuristics that scientists use in their daily work. Although our study did not provide firm results for all learners, the relations found between process and product provide some initial support to the hypothesis that students with low initial domain knowledge profit from such an approach.

In general it can be concluded that the learning environments used in this study both succeeded in supporting the acquisition of domain knowledge while maintaining the students' active engagement with the learning environment. Using implicit/explicit heuristics in the design of a learning environment seems to be an approach that deserves further investigation, especially with respect to the influence of offering explicit heuristics on students' self regulation and to the parallel 
development of domain knowledge and knowledge about science. There is some evidence indicating that the explicit heuristics triggered more self-regulation in students. This could mean that students incorporated the heuristics in their existing knowledge structures. Whether this is really the case could be investigated in a study in which, heuristic knowledge is explicitly measured and students are also exposed to discovery learning transfer task without support after their initial learning experience.

\section{References}

ACT. (2001). Act science test, example science tests questions. Retrieved April, 25, 2005, from http://www.actstudent.org/sampletest/index.html

Chen, Z., \& Klahr, D. (1999). Al other things being equal: Children's acquisition of the control of variables strategy. Child Development, 70, 1098-1120.

de Jong, T. (1991). Learning and instruction with computer simulations. Education \& Computing, 217-229.

de Jong, T., \& van Joolingen, W. R. (1998). Scientific discovery learning with computer simulations of conceptual domains. Review of Educational Research, 68, 179-202.

Friedler, Y., Nachmias, R., \& Linn, M. C. (1990). Learning scientific reasoning skills in microcomputer-based laboratories. Journal of Research in Science Teaching, 27, 173-191.

Glaser, R., Schauble, L., Raghavan, K., Zeitz, C., \&. In, \& (Eds.), (pp.). (1992). Scientific reasoning across different domains. In E. D. Corte, M. Linn, H. Mandl \& L. Verschaffel (Eds.), Computer-based learning environments and problem solving (pp. 345-373). Berlin: Springer-Verlag.

Hodson, D. (1996). Laboratory work as scientific method: Three decades of confusion and distortion. Journal of Curriculum studies, 28, 115-135. 
Hodson, D. (1998). Science fiction: The continuing misrepresentation of science in the school curriculum. Curriculum studies, 6(2), 191-216.

Klahr, D., \& Dunbar, K. (1988). Dual space search during scientific reasoning. Cognitive Science, 12, 1-48.

Klahr, D., Fay, A. L., \& Dunbar, K. (1993). Heuristics for scientific experimentation: A developmental study. Cognitive psychology, 25, 11-146.

Krajcik, J., Blumenfeld, P. C., Marx, R. W., Bass, K. M., Fredericks, J., \& Soloway, E. (2000). Instructional, curricular, and technological supports for inquiry in science classrooms. In J. Minstrell \& E. H. v. Zee (Eds.), Inquiring into inquiry learning and teaching in science (pp. 283-315). Washington, D.C: AAAS.

Kuhn, D., Black, J., Keselman, A., \& Kaplan, D. (2000). The development of cognitive skills to support inquiry learning. Cognition and Instruction, 18, 495-523.

Kuhn, D., Schauble, L., \& Garcia-Mila, M. (1992). Cross-domain development of scientific reasoning. Cognition and Instruction, 9, 285- 327.

Kulkarni, D., \& Simon, H. A. (1988). The processes of scientific discovery: The strategy of experimentation. Cognitive Science, 12, 139-175.

Lajoie, S. P., \& Derry, S. J. (Eds.). (1993). Computers as cognitive tools. Hillsdale, NJ: Lawrence Erlbaum Associates.

Langley, P. (1981). Data-driven discovery of physical laws. Cognitive Science, 5, 3154.

Lavoie, D. R., \& Good, R. (1988). The nature and use of predictions skills in a biological computer simulation. Journal of Research in Science Teaching, 25, 335-360. 
Lewis, M., Bishay, M., \& McArthur, D. (1993). The macrostructure and microstructure of inquiry activities: Evidence from students using a microworld for mathematical discovery. In P.Brna, S.Ohlson \& H.Pain (Eds.), Proceedings of ai-ed'93, world conference on artificial intelligence and education, 23-27 august 1993 (pp. 169-176). Edinburgh: AACE, Charlottesville.

Mayer, R. E. (2004). Should there be a three-strikes rule against pure discovery learning? American Psychologist, 59, 14-19.

Minstrell, J. (2000). Implications for teaching and learning inquiry: A summary. In J. Minstrell \& E. H. v. Zee (Eds.), Inquiring into inquiry learning and teaching in science (pp. 471-496). Washington, D.C: AAAS.

Njoo, M., \& de Jong, T. (1993). Exploratory learning with a computer simulation for control theory: Learning processes and instructional support. Journal of Research in Science Teaching, 30, 821-844.

Polya, G. (1945). How to solve it. Princeton, NJ: Princeton University Press.

Polya, G. (1971). Methodology or heuristics, strategy or tactics? Archives de Philosophie, 34, 623-629.

Quinn, J., \& Alessi, S. (1994). The effects of simulation complexity and hypothesis generation strategy on learning. Journal of Research on Computing in Education, 27, 75-91.

Reimann, P. (1991). Detecting functional relations in a computerized discovery environment. Learning \& Instruction, 1, 45-65.

Rivers, R. H., \& Vockell, E. (1987). Computer simulations to stimulate scientific problem solving. Journal of Research in Science Teaching, 24, 403-415. 
Sanders, I., Bouwmeester, M., \& Blanken, M. v. (2000). Heuristieken voor experimenteren in ontdekkend leeromgevingen. [heuristics for experimenting in discovery learning environments] (Unpublished report). Enschede: University of Twente.

Schauble, L., Glaser, R., Duschl, R. A., Schulze, S., \& John, J. (1995). Students' understanding of the objectives and procedures of experimentation in the science classroom. The Journal of the Learning Sciences, 4, 131-166.

Schauble, L., Glaser, R., Raghavan, K., \& Reiner, M. (1991). Causal models and experimentation strategies in scientific reasoning. The Journal of the Learning Sciences, 1, 201-239.

Schoenfeld, A. (1979). Can heuristics be taught? In J. Lochhead \& J. Clement (Eds.), Cognitive process instruction (pp. 315-338). Philadelphia: Franklin Institute Press.

Schoenfeld, A. (1985). Mathematical problem solving. New York: Academic Press.

Schunn, C. D., \& Anderson, J. R. (1999). The generality/specificity of expertise in scientific reasoning. Cognitive Science, 23, 337-370.

Shute, V. J., \& Glaser, R. (1990). A large-scale evaluation of an intelligent discovery world: Smithtown. Interactive Learning Environments, 1, 51-77.

Swaak, J., \& de Jong, T. (2001). Discovery simulations and the assessment of intuitive knowledge. Journal of Computer Assisted Learning, 20, 225-234.

Swaak, J., de Jong, T., \& van Joolingen, W. R. (2004). The effects of discovery learning and expository instruction on the acquisition of definitional and intuitive knowledge. Journal of Computer Assisted Learning, 20, 225-234.

Tsirgi, J. E. (1980). Sensible reasoning: A hypothesis about hypotheses. Child Development, 51, 1-10. 
van Joolingen, W. R. (1999). Cognitive tools for discovery learning. International Journal of Artificial Inteligence in Education, 10, 385-397.

van Joolingen, W. R., \& de Jong, T. (1991). Characteristics of simulations for instructional settings. Education \& Computing, 6, 241-262.

van Joolingen, W. R., \& de Jong, T. (1997). An extended dual search space model of learning with computer simulations. Instructional Science, 25, 307-346.

Veermans, K. H., de Jong, T., \& van Joolingen, W. R. (2000). Promoting self directed learning in simulation based discovery learning environments through intelligent support. Interactive Learning Environments, 8, 229-255.

White, B. Y. (1993). Thinkertools: Causal models, conceptual change, and science education. Cognition and Instruction, 10, 1-100.

White, B. Y., \& Frederiksen, J. R. (1990). Causal model progressions as a foundation for intelligent learning environments. Artificial Intelligence, 42, 99 -57.

Zachos, P., Hick, L. T., Doane, W. E. J., \& Sargent, S. (2000). Setting theoretical and empirical foundations for assessing scientific inquiry and discovery in educational programs. Journal of Research in Science Teaching, 37, 938-962.

Zohar, A. (1995). Reasoning about interactions between variables. Journal of Research in Science Teaching, 32, 1039-1063. 


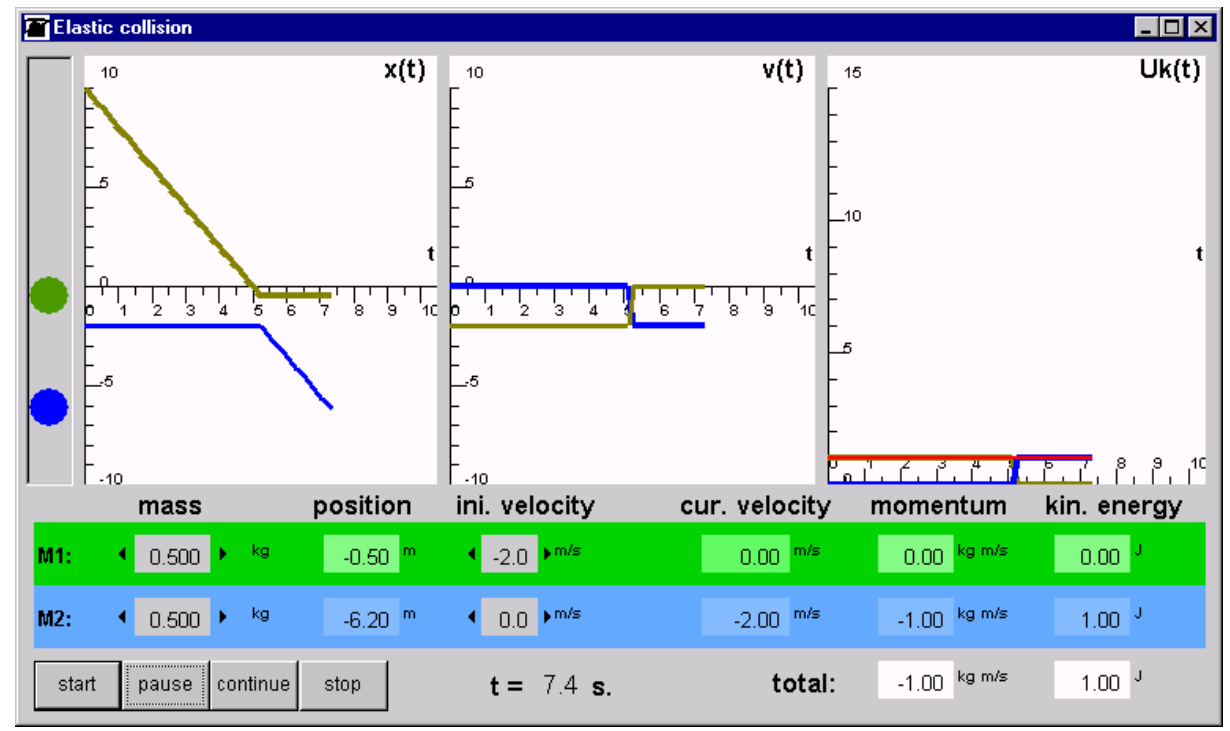

Figure 1. Elastic collision simulation window. 


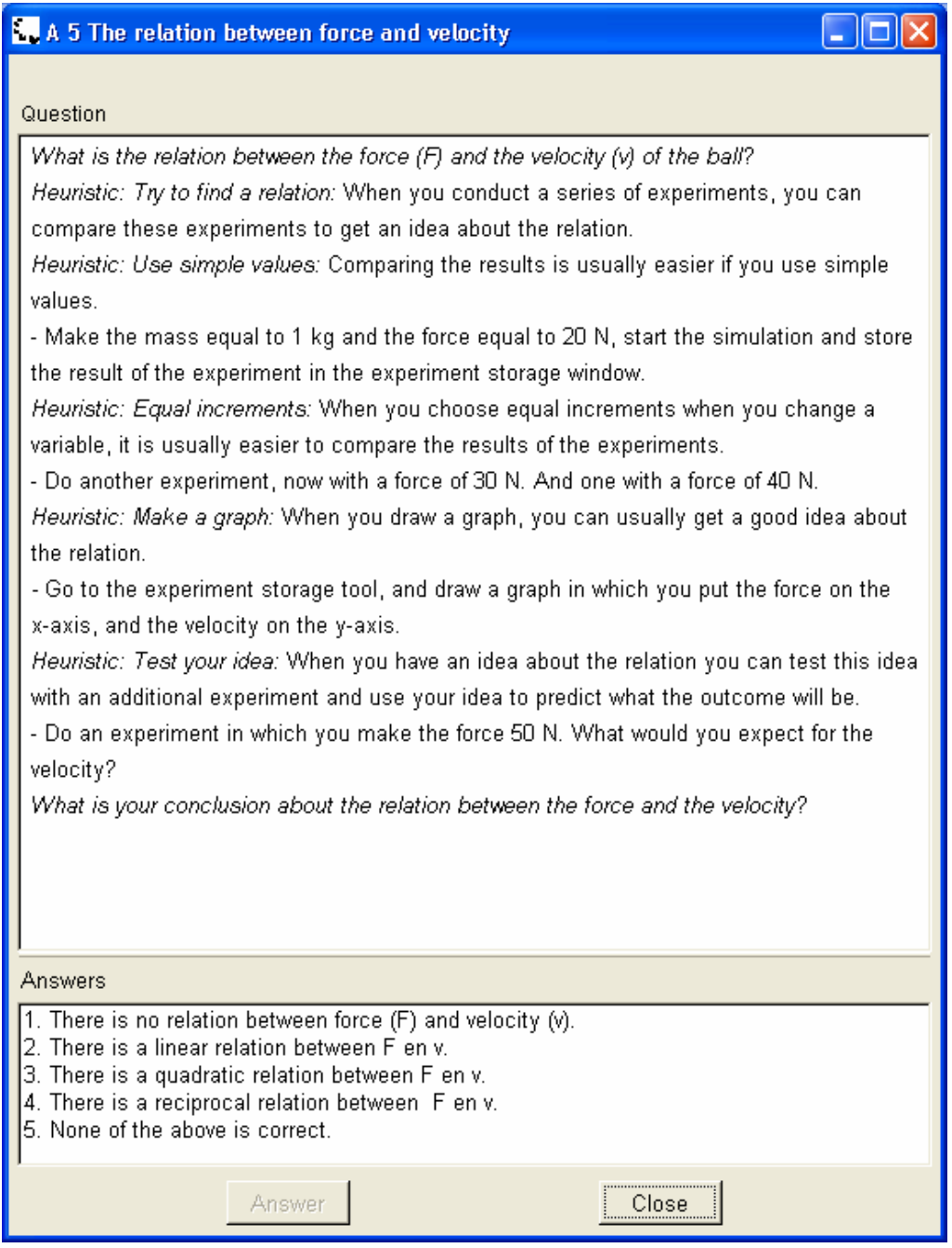

\begin{tabular}{|c|c|}
\hline \multicolumn{2}{|l|}{ Question } \\
\hline \multicolumn{2}{|c|}{$\begin{array}{l}\text { What is the relation between the force }(F) \text { and the } \\
\text { velocity ( } V \text { ) of the ball? } \\
\text { - Make the mass equal to } 1 \mathrm{~kg} \text { and the force equal to } \\
20 \mathrm{~N} \text {, start the simulation and store the result of the } \\
\text { experiment in the experiment storage window. } \\
\text { - Do the same but now with a force of } 30 \mathrm{~N} \text {. And } \\
\text { another time with a force of } 40 \mathrm{~N} \text {. And one time with a } \\
\text { force of } 50 \mathrm{~N} \text {. } \\
\text { - Go to the experiment storage tool, and draw a graph } \\
\text { in which you put the force on the } \mathrm{x} \text {-axis, and the } \\
\text { velocity on the } \mathrm{y} \text {-axis. } \\
\text { What is your conciusion about the relation between the } \\
\text { force and the velocity? }\end{array}$} \\
\hline \multicolumn{2}{|l|}{ Answers } \\
\hline \multicolumn{2}{|c|}{$\begin{array}{l}\text { 1. There is no relation between force }(F) \text { and velocity (v). } \\
\text { 2. There is a linear relation between } F \text { en } v \text {. } \\
\text { 3. There is a quadratic relation between } F \text { en } v \text {. } \\
\text { 4. There is a reciprocal relation between } F \text { en } v \text {. } \\
\text { 5. None of the above is correct. }\end{array}$} \\
\hline Answer & Close \\
\hline
\end{tabular}

Figure 2. Example of an assignment in two versions. On the left the version that was used within the learning environment with explicit heuristics, on the right, the same assignment in the version for the implicit heuristics environment. 

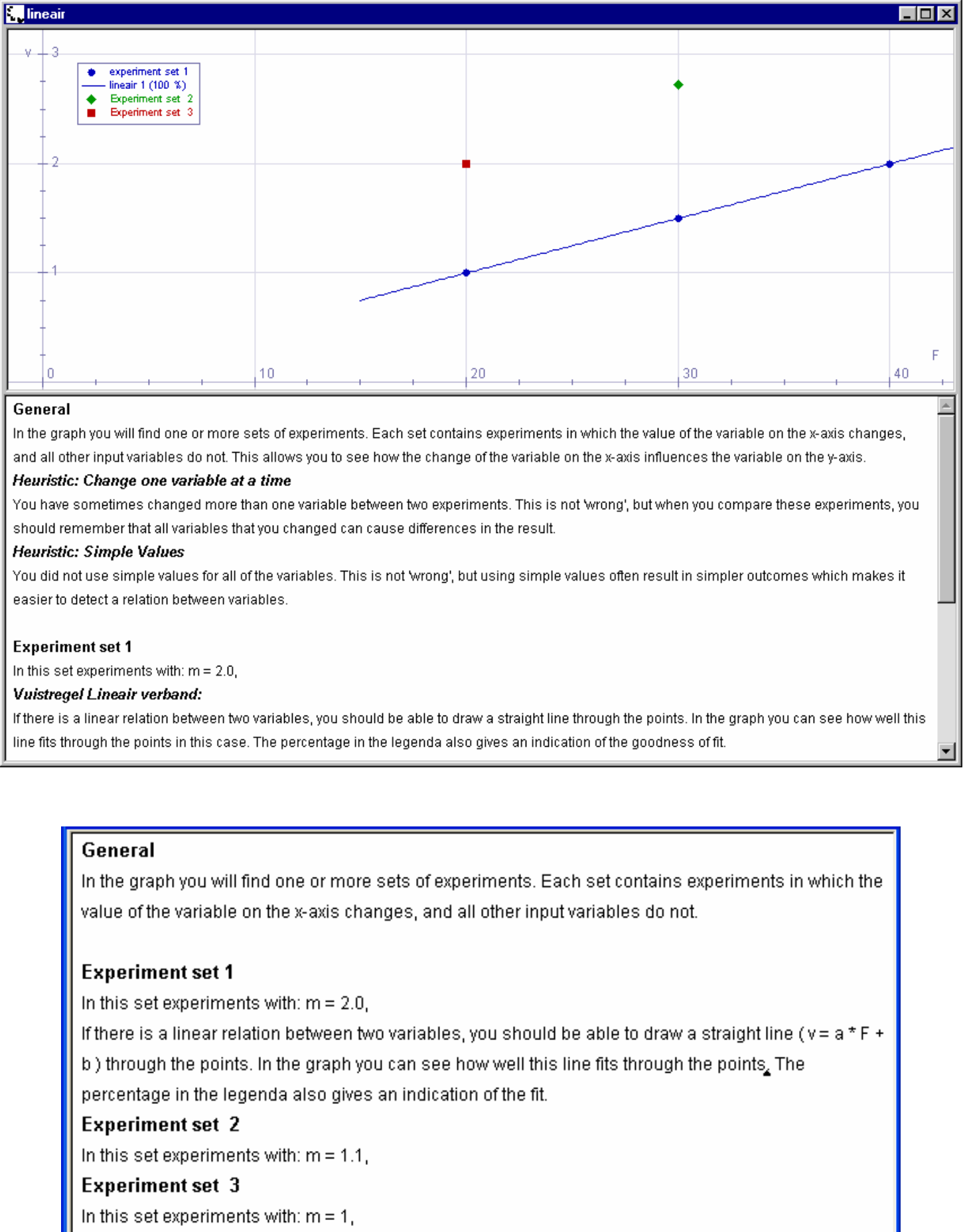

Figure 3. Example of a graph with feedback given to the students. The top version of the feedback is given to the explicit heuristic condition, the bottom version to the implicit heuristic condition. 
Question 15

A scientist investigates learning effects in monkeys. He has the monkey's search for a banana in a maze, and measures how long it takes before they find the banana. The results are shown in the graph.

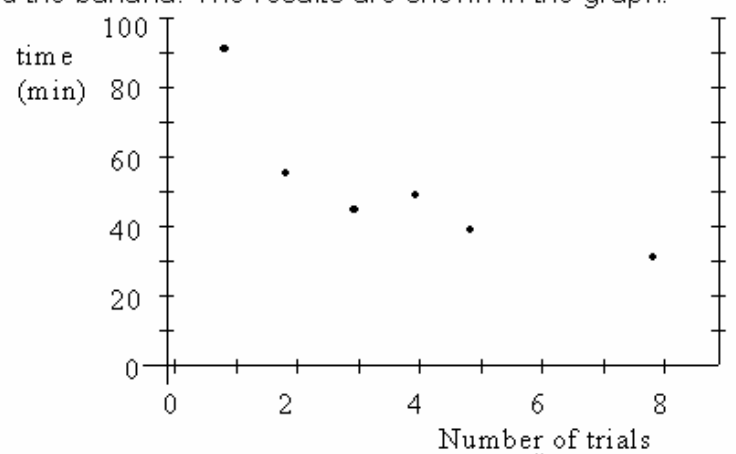

How long will the monkeys need on the $10^{\text {th }}$ trial?
A. 50 minutes
B. 31 minutes
C. 28 minutes

D. 10 minutes

Figure 4. Example question from the scientific reasoning test. 


\section{Table 1}

\section{Heuristics used in the design of the learning environment}

\begin{tabular}{|c|c|}
\hline Simplify problem & $\begin{array}{l}\text { Simplify the problem, or try to solve part of the problem (Polya, 1945; } \\
\text { Schoenfeld, 1985) }\end{array}$ \\
\hline $\begin{array}{l}\text { Identify } \\
\text { Hypothesis }\end{array}$ & $\begin{array}{l}\text { Generate a small amount of data and examine for a candidate rule or relation. } \\
\text { (Glaser et al., 1992) }\end{array}$ \\
\hline $\begin{array}{l}\text { Slightly modify } \\
\text { Hypothesis }\end{array}$ & $\begin{array}{l}\text { Address slightly modified problems: Weaken or strengthen conditions slightly in } \\
\text { reformulating hypotheses (Glaser et al., 1992) }\end{array}$ \\
\hline Set expectations & $\begin{array}{l}\text { Expectations for a class are used, as expectations for members of the class not } \\
\text { previously tested or if a law in one context is found, expect a similar form of law } \\
\text { to hold in a new context. (Kulkarni \& Simon, 1988; Langley, 1981) }\end{array}$ \\
\hline$\overline{\text { VOTAT }}$ & $\begin{array}{l}\text { If a variable is not relevant for the hypothesis under, test then hold that variable } \\
\text { constant, or vary one thing at a time (VOTAT), or If not varying a variable, then } \\
\text { pick the same value as used in the previous experiment (Glaser et al., 1992; } \\
\text { Klahr \& Dunbar, 1988; Schunn \& Anderson, 1999; Tsirgi, 1980) }\end{array}$ \\
\hline Simple values & $\begin{array}{l}\text { Design experiments giving characteristic results. (Klahr et al., 1993) } \\
\text { Choose special cases, set any parameter to 1,2,3 (Schoenfeld, 1979) }\end{array}$ \\
\hline Equal increments & $\begin{array}{l}\text { If choosing a third value for a variable, then choose an equal increment as } \\
\text { between first and second values. } \\
\text { Or if manipulating a variable, then choose simple, canonical manipulations } \\
\text { (Schunn \& Anderson, 1999) }\end{array}$ \\
\hline $\begin{array}{l}\text { Confirm } \\
\text { Hypothesis }\end{array}$ & $\begin{array}{l}\text { Generate several additional cases in an attempt to either confirm or disconfirm } \\
\text { the hypothesized relation (Glaser et al., 1992) }\end{array}$ \\
\hline Extreme values & $\begin{array}{l}\text { Try some extreme values to see if there are limits on the proposed relationship } \\
\text { (Schunn \& Anderson, 1999) }\end{array}$ \\
\hline Make a graph & $\begin{array}{l}\text { If you have a number of data points with values for variables, then make a graph } \\
\text { to get an indication about the nature of the relationship. (Polya, 1945) }\end{array}$ \\
\hline Present evidence & $\begin{array}{l}\text { If you state a conclusion about a certain hypothesis present evidence to support } \\
\text { that conclusion (Schoenfeld, 1985) }\end{array}$ \\
\hline Keep track & $\begin{array}{l}\text { Keep records of what you are doing. (Klahr \& Dunbar, 1988; Kulkarni \& Simon, } \\
\text { 1988; Schauble et al., 1991) }\end{array}$ \\
\hline
\end{tabular}


HEURISTICS TO FACILITATE DISCOVERY LEARNING 33

Table 2

Mean scores and standard deviations (between brackets) for the different knowledge

\begin{tabular}{|c|c|c|c|c|c|c|}
\hline & \multicolumn{2}{|c|}{ Explicit } & \multicolumn{2}{|c|}{ Implicit } & \multicolumn{2}{|l|}{ Total } \\
\hline & Pre & Post & Pre & Post & Pre & Post \\
\hline$\overline{\text { Definitional }}$ & 10.9 & 15.6 & 10.6 & 15.2 & 10.8 & 15.4 \\
\hline$(\max =20)$ & $(2.1)$ & $(2.4)$ & $(3.1)$ & $(2.8)$ & $(2.6)$ & $(2.6)$ \\
\hline Intuitive & 16.9 & 21.1 & 16.8 & 20.7 & 16.9 & 20.9 \\
\hline$(\max =24)$ & (3.8) & $(1.9)$ & (3.9) & $(2.9)$ & (3.8) & $(2.4)$ \\
\hline Scientific reasoning test & & 12.6 & & 12.4 & & 12.5 \\
\hline$(\max =15)$ & & $(1.1)$ & & $(1.1)$ & & $(1.1)$ \\
\hline Experiment design & & 3.1 & & 3.0 & & 3.0 \\
\hline$(\max =5)$ & & $(1.5)$ & & $(1.0)$ & & $(1.2)$ \\
\hline
\end{tabular}


HEURISTICS TO FACILITATE DISCOVERY LEARNING 34

Table 3

Correlations between the pre-test scores and the post-test scores on the knowledge tests

\begin{tabular}{llllll}
\hline & & Definitinal & Intuitive & Scientific & Experiment \\
& & post-test & Post-test & reasoning test & design \\
\cline { 2 - 6 } Definitional & Explicit & -0.11 & 0.40 & 0.50 & 0.09 \\
\cline { 2 - 6 } pre-test & Implicit & $0.59^{*}$ & 0.17 & -0.10 & 0.09 \\
\hline Intuitive & Explicit & 0.44 & 0.45 & $0.61^{*}$ & 0.26 \\
\cline { 2 - 6 } pre-test & Implicit & $0.52^{*}$ & $0.57^{*}$ & -0.13 & 0.43 \\
\hline
\end{tabular}

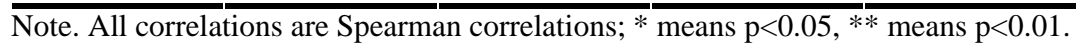


HEURISTICS TO FACILITATE DISCOVERY LEARNING 35

Table 4

Regression analyses predicting definitional post-test scores based on pre-test scores on the knowledge tests

\begin{tabular}{|c|c|c|c|c|c|c|c|c|c|c|}
\hline \multirow{3}{*}{$\begin{array}{l}\text { Definitional } \\
\text { test }\end{array}$} & \multicolumn{5}{|l|}{ Explicit } & \multicolumn{5}{|l|}{ Implicit } \\
\hline & Sum & & Mean & & & Sum & & Mean & & \\
\hline & Square & Df & Square & $\mathrm{F}$ & Sig. & Square & Df & Square & $\mathrm{F}$ & Sig. \\
\hline Regression & 19.7 & 2 & 9.87 & 1.92 & 0.193 & 50.4 & 2 & 25.2 & 4.74 & 0.033 \\
\hline Residual & 56.6 & 11 & 5.15 & & & 58.5 & 11 & 5.31 & & \\
\hline Total & 76.4 & 13 & & & & 109 & 13 & & & \\
\hline
\end{tabular}

Note. The regression functions for predicting the post-test score are:

Explicit: definitional post $=9.63+0.06 *$ definitional pre-test $+0.33 *$ intuitive pre-test .

Implicit: definitional post $=5.67+0.52 *$ definitional pre-test $+0.23 *$ intuitive pre-test . 
HEURISTICS TO FACILITATE DISCOVERY LEARNING 36

Table 5

Regression analyses predicting intuitive post-test scores based on pre-test scores on the knowledge tests

\begin{tabular}{|c|c|c|c|c|c|c|c|c|c|c|}
\hline \multirow[b]{3}{*}{ Intuitive test } & \multicolumn{5}{|l|}{ Explicit } & \multicolumn{5}{|l|}{ Implicit } \\
\hline & Sum & & Mean & & & Sum & & Mean & & \\
\hline & Square & $\mathrm{Df}$ & Square & $\mathrm{F}$ & Sig. & Square & Df & Square & $\mathrm{F}$ & Sig. \\
\hline Regression & 14.6 & 2 & 7.28 & 2.64 & 0.116 & 70.8 & 2 & 35.4 & 9.61 & 0.004 \\
\hline Residual & 30.4 & 11 & 2.76 & & & 40.5 & 11 & 3.68 & & \\
\hline Total & 44.9 & 13 & & & & 111 & 13 & & & \\
\hline
\end{tabular}

Note. The regression functions for predicting the post-test score are:

Explicit: intuitive post $=13.97+0.30 *$ definitional pre-test $+0.23 *$ intuitive pre-test.

Implicit: intuitive post $=10.32+0.06 *$ definitional pre-test $+0.57 *$ intuitive pre-test. 
Table 6

Process data from the first level (force ,mass, velocity). Means, standard deviations and t-Test comparison

\begin{tabular}{lcccccccc}
\hline & \multicolumn{7}{c}{ Implicit } & \multicolumn{5}{c}{ Explicit } & & \\
& & Mean & SD & Mean & SD & T & df & p \\
\cline { 2 - 8 } & & & & & & & \\
Total time (s) & 2289 & $(373)$ & 2292 & $(558)$ & -0.02 & 27 & 0.987 \\
Time on assignments (s) & 1552 & $(300)$ & 1521 & $(443)$ & 0.22 & 27 & 0.827 \\
Total experiments & 29.7 & $(10.2)$ & 32.4 & $(9.6)$ & 0.75 & 27 & 0.459 \\
Total unique experiments & 12.4 & $(4.79)$ & 16.3 & $(6.83)$ & -1.78 & 27 & 0.086 \\
Exact experimentation (max $=4)$ & 3.27 & $(0.96)$ & 1.79 & $(1.37)$ & 3.35 & 23.2 & $0.003^{* *}$ \\
Assignments with graphs & 3.13 & $(0.64)$ & 2.36 & $(1.22)$ & 2.13 & 19.4 & $0.046^{*}$ \\
\hline
\end{tabular}

Note. * means $\mathrm{p}<0.05, * *$ means $\mathrm{p}<0.01$. 


\section{Table 7}

Number of students that follow the heuristics in the assignments on the first level exactly

\begin{tabular}{lcccc}
\hline & \multicolumn{2}{c}{ Explicit (n=13) } & \multicolumn{2}{c}{ Implicit (n=15) } \\
\cline { 2 - 5 } Assignment & 7 & Graph & Experimentation & Graph \\
\hline A 3 tangent x(t)-velocity & 3 & 10 & 13 & 12 \\
A 4 mass-velocity & 6 & 11 & 14 & 15 \\
A 5 force-velocity & 10 & n.a. & 14 & n.a. \\
A 6 formula velocity & & & & \\
\hline
\end{tabular}


HEURISTICS TO FACILITATE DISCOVERY LEARNING 39

Table 8

Correlations between the definitional post-test score and process measures for elastic and inelastic collisions

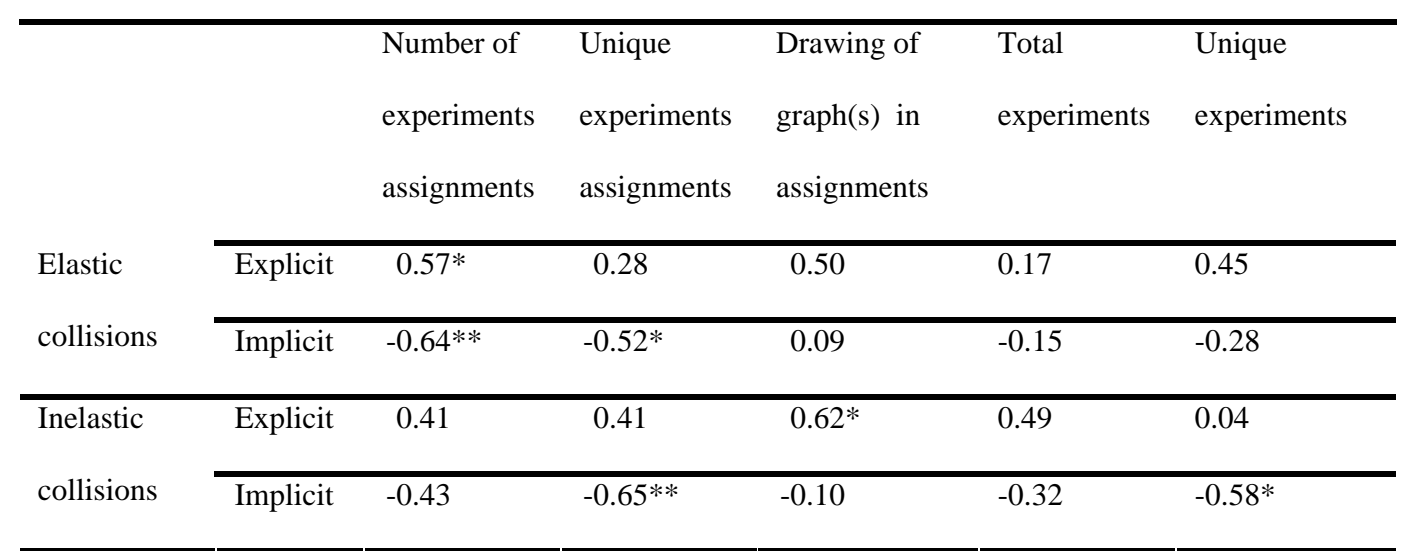

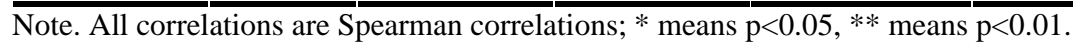

